\title{
V - wie verzwickte Vorgänge auflösen
}

\author{
In der Praxis-Buchhaltung sind häufig komplexe Abläufe darzustellen, die den Zahnarzt vor die \\ Frage stellen: Wie kann dieser verzwickte Vorgang in Buchungssätze aufgelöst werden. Schritt- \\ weises Vorgehen kann die Lösung sein.
}

Um komplexe Vorgänge aufzudröseln, empfiehlt es sich, das Ereignis Schritt für Schritt zu rekonstruieren. Danach sollte überprüft werden, ob Buchungsbedarf besteht und dies dann per Buchung abgebildet werden. Der hilfreiche Kernsatz „Was geschah in Wirklichkeit?“ unterstützt bei der gedanklichen Strukturierung des Ablaufs.

Als Beispiel ist hier die Aufnahme eines Darlehens für die Anschaffung von Anlagevermögen benannt. Aus dem täglichen Feedback von Anwendern wird deutlich, dass dieser Fall typisch für eine Praxisbuchhaltung ist und immer wieder die Frage der buchhalterischen Umsetzung aufwirft. Das schrittweise Vorgehen sieht wie folgt aus:

1. Aufnahme eines Darlehens bei Bank X - vereinbart wird, dass die Auszahlung nach Vorlage der Rechnungen jeweils in Rechnungshöhe auf das Girokonto der Praxis erfolgen soll. Die Praxis wird danach die Rechnung beim Verkäufer begleichen. Buchungsbedarf: keine Darstellung in der Buchhaltung, Anlage eines neuen Darlehenskontos im Kontenplan (Kontenklasse 0).

2. Nach Abschluss des Kaufvertrags und Zugang der Rechnung legt die Praxis diese der Bank vor. Es erfolgt die Auszahlung des Rechnungsbetrags auf das Girokonto. Buchungsbedarf: Gebucht werden der Zahlungseingang auf dem Girokonto so-

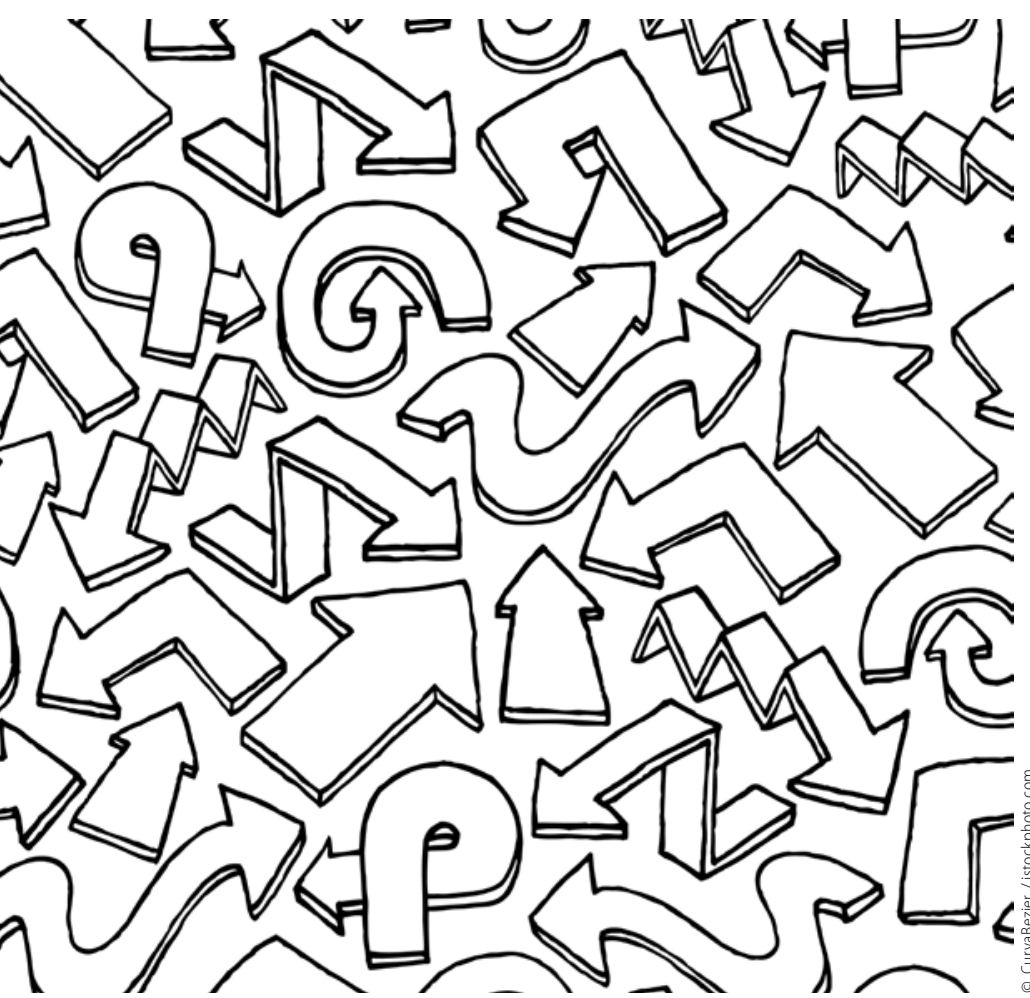

wie die entstandene Darlehensverbindlichkeit (Buchungssatz: Bank an Darlehen).

3. Die Praxis veranlasst die Überweisung des Rechnungsbetrags an den Verkäufer. Buchungsbedarf: In der Regel wird es sich um die Anschaffung eines Anlageguts handeln, das in einem Anlagenkonto der Kontenklasse 0 gebucht wird. Der Einnahmenüberschussrechner (auch $\$ 3 / 4$-Rechner genannt) bucht die Vorgänge regelmäßig dann, wenn sie im Finanzverkehr vorkommen. Bei Belastung des Rechnungsbetrags auf dem Bankkonto wird das Anlagegut buchhalterisch erfasst (Buchungssatz: Anlagekonto an Bank).

Auch bei allen anderen Vorgängen, bei denen eine Verbuchung zunächst unübersichtlich erscheint, ist diese Vorgehensweise empfehlenswert.

Das in den Artikeln dargestellte Buchhaltungskonzept basiert auf der zahnarztspezifischen Buchhaltungssoftware fibu-doc und wird vom FVDZ unterstützt.

\section{Seminare}

Personalmanagement

12.10.2016, Essen

Praxisbuchhaltung leicht und verständlich (Theorie) 14.10.2016, Münster

Einstieg in die Buchhaltung mit fibu-doc (EDV-Schulung) 15.10.2016, Münster

Der Blick in die Praxiszahlen 26.10.2016, Düsseldorf

Personalmanagement

11.11.2016, Berlin

Der Blick in die Praxiszahlen

30.11.2016, Leipzig

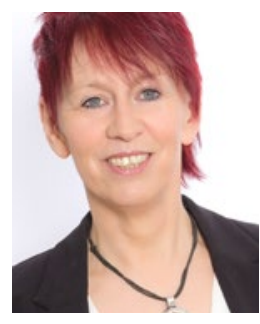

Barbara Mertens

www.fibu-doc.de 